\title{
Hepatitis E virus and neurological disorders
}

\author{
Brendan N Mclean, ${ }^{1}$ James Gulliver, ${ }^{2}$ Harry R Dalton ${ }^{2,3}$
}

\begin{abstract}
${ }^{1}$ Neurology Department, The Royal Cornwall Hospitals NHS Trust, Truro, UK

${ }^{2}$ Gastroenterology Department, The Royal Cornwall Hospitals NHS Trust, Truro, UK ${ }^{3}$ European Centre for Environment and Human Health, University of Exeter, Truro, UK

\section{Correspondence to}

Dr Brendan N Mclean, Neurology Department, The Royal Cornwall Hospitals NHS Trust, Truro, TR1 3L, UK; brendan.mclean@nhs. net
\end{abstract}

Accepted 10 April 2017
To cite: Mclean BN, Gulliver J, Dalton HR. Pract Neurol 2017;17:282-288.

\begin{abstract}
Hepatitis $E$ is the most common cause of hepatitis worldwide. While originally considered a disease of developing countries, it is increasingly recognised in developed countries, probably related to contaminated pork meat, and where infection is often asymptomatic. However, several non-liver manifestations have become apparent, the most important of which are neurological, including Guillain-Barré syndrome (acute inflammatory demyelinating polyradiculoneuropathy (AIDP)), neuralgic amyotrophy and meningoencephalitis. We recommend testing all patients with AIDP and neuralgic amyotrophy for hepatitis $E$ and consider testing any patient with an unexplained neurological illness and abnormal liver function tests for the virus.
\end{abstract}

\section{INTRODUCTION}

The naming of a viral illness often reflects some aspect of the disease it causes. Yellow fever, glandular fever, hand foot and mouth are self-evident, descriptive labels. The group of viral illnesses bearing the name 'hepatitis' should, therefore, signal primarily a liver disorder, and any extrahepatic features represent a secondary phenomenon. This holds true for hepatitis $\mathrm{A}, \mathrm{B}, \mathrm{C}$ and D and until recently was believed to be the case for hepatitis $\mathrm{E}$ virus (HEV). In this article, we demonstrate that HEV has other, perhaps more significant, neurological associations and that we ought to be alert to HEV as a neurotropic virus.

\section{HEPATITIS E IN DEVELOPING COUNTRIES}

HEV is the most common cause of hepatitis worldwide. ${ }^{1}$ It is a non-enveloped single-stranded RNA virus of the genus hepesvirus. It was originally thought to be a disease of developing countries, where genotypes 1 and 2 predominate, and where it is an obligate human pathogen transmitted by ingestion of faecally contaminated water. The illness usually affects young adults and is usually self-limiting, except in pregnant women where the mortality is $25 \%$. Sporadic cases are commonplace, but occasional spectacular outbreaks occur involving hundreds or thousands of cases. ${ }^{2}$ Such outbreaks usually result from the breakdown in sanitary infrastructure, as in the recent outbreaks in the refugee camps in South Sudan. ${ }^{3}$

\section{ZOONOTIC HEV IN DEVELOPED COUNTRIES}

Recently, it has been recognised that HEV is also endemic in developed countries, including Europe, where genotypes 3 and 4 predominate. In these areas, HEV is largely a porcine zoonosis. ${ }^{4}$ One important route of transmission is via contaminated pork meat, as HEV has been found in pork products in the human food chain in many countries in Europe, USA and Japan (figure 1). It takes cooking temperatures of $71^{\circ} \mathrm{C}$ for 20 min to inactivate HEV completely. ${ }^{5} 6$ In the UK, it is unlikely that the average sausage is cooked within these parameters. In developed countries, zoonotic hepatitis $\mathrm{E}$ tends to cause an acute hepatitis in older men or result in a chronic infection in immunocompromised patients, including solid organ transplant recipients, patients with haematological malignancy and people with HIV. $^{7} 8$ Chronically infected patients have no symptoms, but develop rapidly progressive cirrhosis: if left untreated, $10 \%$ are cirrhotic within 2 years. The prevalence of chronic infection with HEV varies between countries, but is between 1\% and $2 \%$ in most European transplant centres. Chronic infection occurs with any type of organ transplant and in children as well as adults. ${ }^{2}$ 


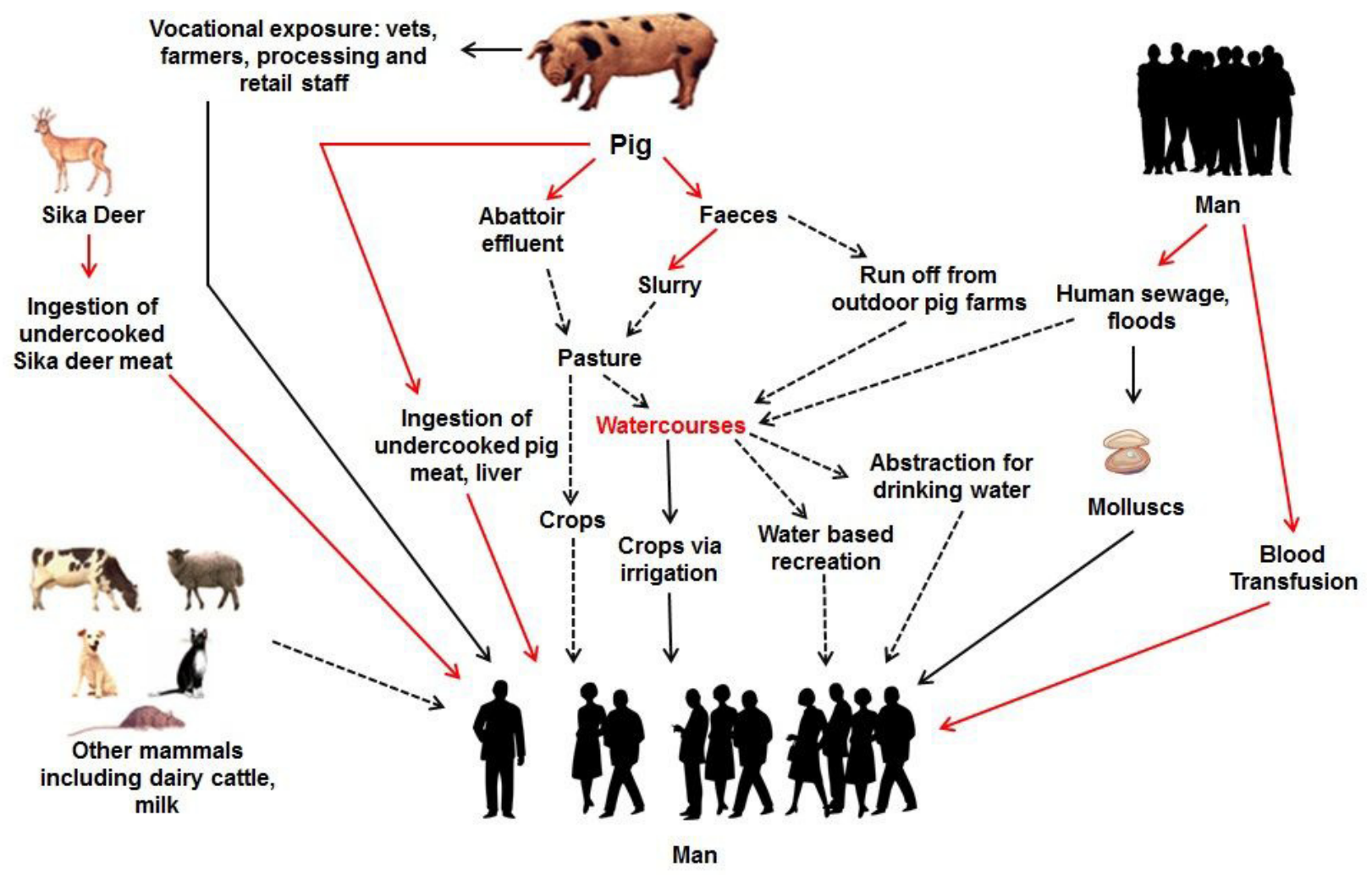

Figure 1 Zoonotic hepatitis E virus (HEV): sources and routes of infection. The red lines are proven routes of infection. The black lines are probable routes of infection. The black dotted lines are possible routes of infection. The pig is considered to be the primary reservoir and is very commonly asymptomatically infected with HEV worldwide.

The incidence of hepatitis $\mathrm{E}$ varies between countries and over time. For example, in the UK, the incidence is $0.2 \%$, but for unknown reasons it is much higher in Southwest France $(2 \%-3 \%){ }^{2}$ These incidence estimates equate to very large numbers of infections, and in England alone there are at least 100000 infections every year. $^{9}$ Most (>95\%) infections are either asymptomatic or unrecognised (figure 2). As the incidence of hepatitis $\mathrm{E}$ is so high and infection is very commonly asymptomatic, it comes as no great surprise that HEV has found its way into the blood supply. What has astonished many observers is the frequency with which this occurs (table 1).

The number of blood donors who are viraemic at the time of donation ranges from 1 in 600 in the Netherlands ${ }^{10}$ to 1 in 14500 in Scotland. ${ }^{11}$ In England, 1 in 2848 donors were viraemic in a study from 2013 to 2014. ${ }^{9}$ Targeted screening of blood donors (whose blood/blood products are destined for high-risk groups including the immunosuppressed) started in the UK in February 2016. Initial data suggest that the number of viraemic donors in the UK is an order of magnitude higher than anticipated, particularly so in Scotland. In the UK, donor HEV viraemia rates now approach 1 in $1000 .{ }^{12}$ The reason for this recent upswing in incidence of $\mathrm{HEV}$ in the
UK is unknown, but these data confirm unequivocally that we have currently huge amounts of circulating $\mathrm{HEV}$ in the community (figure 3 ). What is fascinating is that very commonly the viraemic blood donors have normal liver function tests. This is surprising for a virus that is considered to be primarily 'hepatotropic'.

\section{Symptoms}

Most patients with acute hepatitis $\mathrm{E}$ infection have no symptoms. Older men tend to develop symptomatic hepatitis when exposed to HEV for unknown reasons. ${ }^{13}$ The symptoms of hepatitis $\mathrm{E}$ infection are indistinguishable from other forms of acute viral hepatitis (table 2), except an increasing number of patients are being recognised with primarily a neurological illness (see below). Patients with underlying chronic liver disease have a poor prognosis with a mortality of $27 \%{ }^{14}$; their cause of death is usually (sub)acute liver failure.

In chronic infection, the immunosuppressed patients have no symptoms, and the only clue to the diagnosis is a mildly raised serum alanine aminotransferase, typically 200-300 IU/L. Untreated, they present a year or two later with symptoms and signs of chronic liver disease. $^{2}$ 


\section{Diagnosis}

The diagnosis is confirmed by a combination of serology (anti-HEV IgM and IgG) together with HEV PCR. The period of viraemia may only be brief, so a negative PCR does not necessarily exclude the diagnosis. In the UK, hepatitis $\mathrm{E}$ is a notifiable infection by statute (https://www.gov.uk/guidance/notifiablediseases-and-causative-organisms-how-to-report\#listof-notifiable-diseases).

\section{Treatment}

The vast majority of patients with acute HEV require no treatment. In patients with severe hepatitis and/or underlying chronic liver disease, ribavirin therapy causes rapid viral clearance and may be of benefit. ${ }^{15}$

Patients with chronic infection require treatment. In transplant recipients, the first step is to reduce the immunosuppressive therapy. This will achieve viral clearance in about $30 \%$. Where this is not possible or unsuccessful, ribavirin therapy for 3 months is usually successful. ${ }^{1}$

\section{NEUROLOGICAL MANIFESTATIONS}

There have been several extrahepatic manifestations reported with hepatitis E (box 1). The most common are neurological, occurring in $8 \%$ of infections in one study ${ }^{13}$ from Southwest England. The first case of HEV-associated Guillain-Barré syndrome (GBS) was reported in 2000. ${ }^{16}$ This was followed by other case reports, mainly from Asia. HEV-associated neurological injury did not appear on the 'radar' until 2011, with the publication of a series of seven cases from the well characterised cohorts of acute and chronic genotype $3 \mathrm{HEV}$ from Cornwall, UK and Toulouse, France. ${ }^{17}$ Since then, approximately 100 cases of HEV-associated neurological disease have been published. Nearly all are from Europe and Asia, with only one from the USA, which may reflect a bias in testing. Genotypes 1 and 3 are the only strains associated. The illnesses all appear to be monophasic.

\section{Guillain-Barré syndrome}

The association with preceding infection is well recognised in the acute inflammatory demyelinating polyradiculoneuropathy (AIDP) variant of GBS and occurs in up to two-thirds of patients. Campylobacter jejuni is the single most commonly identified agent, and the illness is thought to result from an autoimmune response with cross-reactivity between ganglioside epitopes on the organism and myelin. It has long been recognised that raised liver function tests occur in AIDP. ${ }^{18}$ After several case reports linking HEV and AIDP appeared in the literature, a case-control study of 201 Dutch patients with AIDP

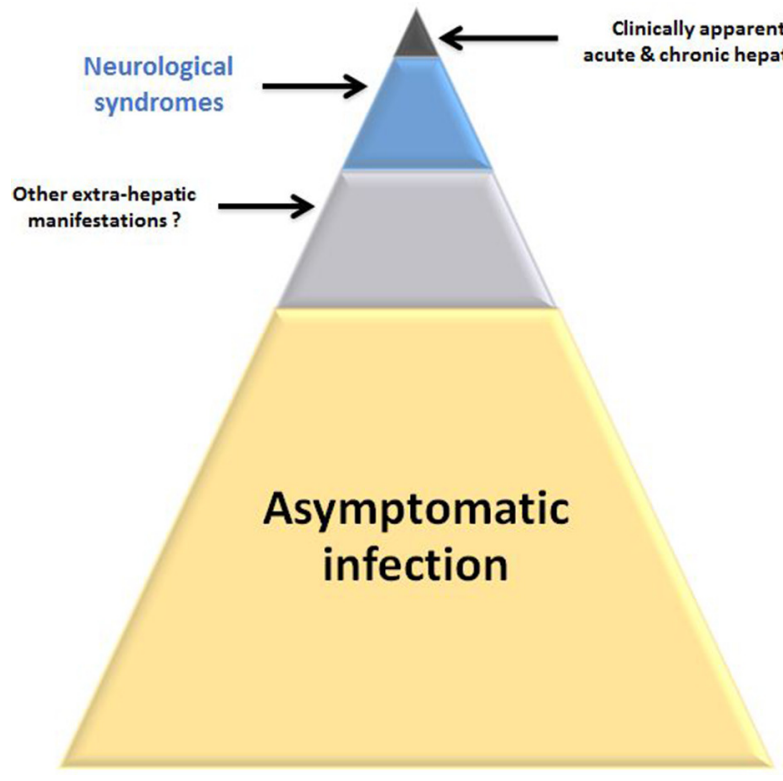

Figure 2 Schematic representation of hepatitis E virus (HEV) genotype 3 in developed countries. The vast majority of cases cause asymptomatic infection. Only a small minority of infections cause clinically apparent hepatitis. The blue/grey areas represent patients who are symptomatic but currently frequently unrecognised. This includes patients with a range of HEVassociated neurological syndromes.

found 5\% with anti-HEV IgM, suggesting recent or active infection, with $0.5 \%$ in 201 controls. ${ }^{19}$ In the HEV-associated cases of GBS, HEV RNA was isolated from the blood in 30\%, none of the patients were jaundiced, and $70 \%$ showed mildly abnormal liver function tests. There were similar findings in studies in Bangladesh, ${ }^{20}$ Japan $^{21}$ and Belgium. $^{22}$ There appears to be no difference in the clinical manifestations and course or outcomes of HEV-related and non-HEV-related AIDP.

Table 1 Hepatitis E virus (HEV) viraemia in blood donors in developed countries

Country Blood donors HEV RNA Reference positive

\begin{tabular}{|c|c|c|}
\hline The Netherlands & $\begin{array}{l}1: 600 \\
1: 2671\end{array}$ & $\begin{array}{l}\text { Hogema et } a l^{31} \\
\text { Slot et } a \beta^{32}\end{array}$ \\
\hline Germany & $1: 1200$ & Vollmer et $\left.a\right|^{33}$ \\
\hline Japan & $1: 1781$ & Fukuda et $\left.a\right|^{34}$ \\
\hline France & $1: 2218$ & Gallian et $a /^{35}$ \\
\hline England & $1: 2848$ & Hewitt et $a l^{9}$ \\
\hline Sweden & $1: 7986$ & Baylis et a/ ${ }^{36}$ \\
\hline Austria & $1: 8416$ & Fischer et $\left.a\right|^{37}$ \\
\hline USA & $1: 9500$ & Stramer et a/ ${ }^{38}$ \\
\hline Scotland & $1: 14520$ & Cleland et $\left.a\right|^{11}$ \\
\hline
\end{tabular}




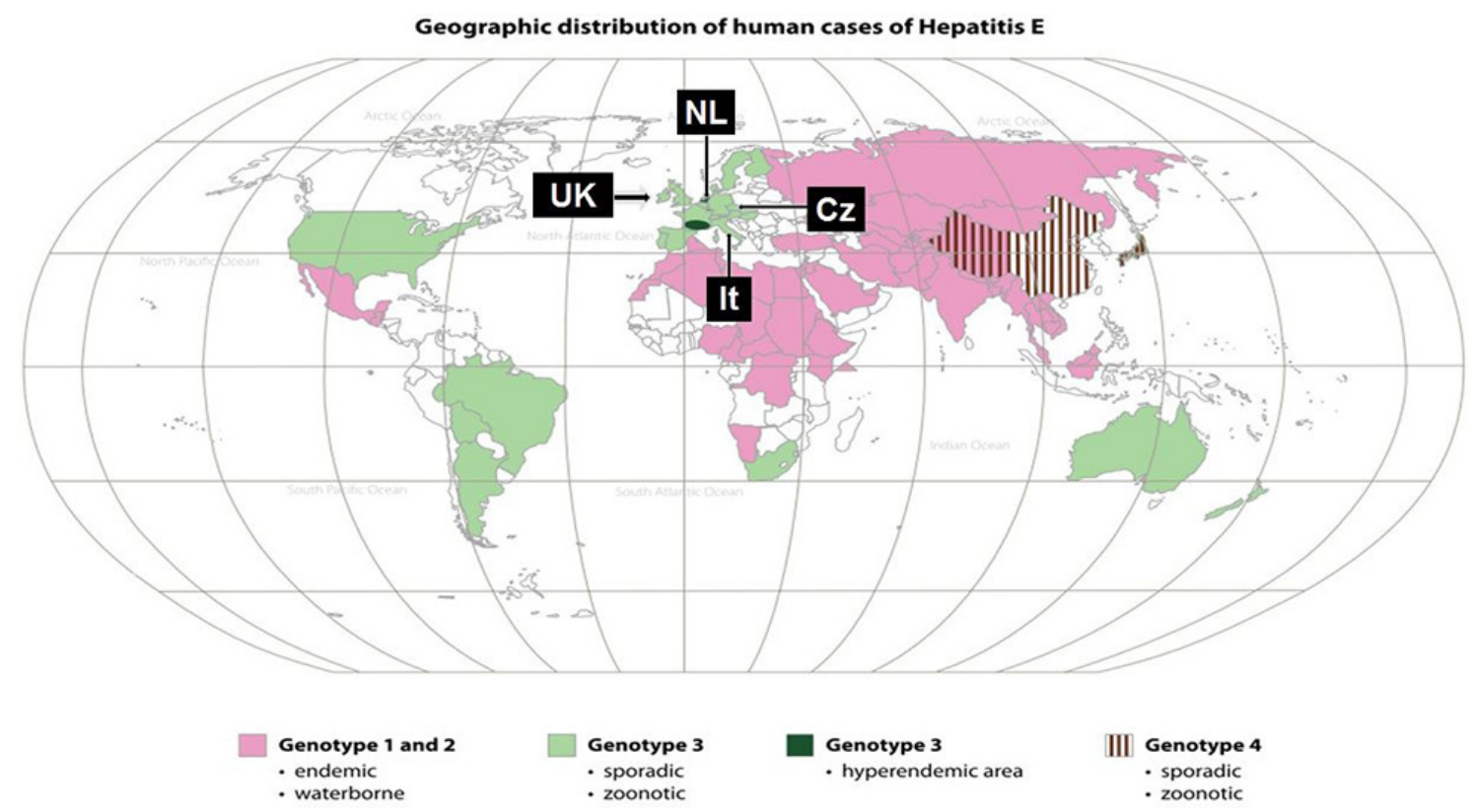

Figure 3 Worldwide distribution of clinical cases of hepatitis E virus (HEV) infection. The Netherlands (NL) and Southwest France (Fr) are considered hyperendemic areas for HEV genotype 3 (black squares). Recent data suggest that the incidence in the UK is now also very high. A large number of cases were also reported in the Czech Republic (Cz) and the seroprevalence in the Abruzzo region of central Italy (It) is nearly $50 \% .^{39}$

\section{Neuralgic amyotrophy}

A significant proportion of patients with neuralgic amyotrophy also report a preceding infection, but no single infective agent predominates. A study of two cohorts of patients from the UK and the Netherlands found that $10 \%$ of patients had acute HEV infection. ${ }^{23}$ The UK cases were retrospectively identified, but those in the Dutch group were from a prospective trial of corticosteroid therapy. All were anicteric, had mildly elevated liver function tests (in some cases they were normal), and in all but one case, HEV RNA (genotype 3 ) was found in the serum. All were locally acquired infections, without a clear source of infection. There have now been over 30 cases of HEV-associated neuralgic amyotrophy reported in the literature, mostly from Europe. ${ }^{24}$

The clinical phenotype of HEV-associated neuralgic amyotrophy appears to be a bilateral disorder in middleaged men, affecting any part of the brachial plexus in a patchy manner. Some patients have lumbosacral and phrenic nerve involvement. The outcome of neuralgic amyotrophy associated with HEV may be less favourable than in those cases not associated with HEV. A multinational study is currently underway to address this issue and clarify the clinical phenotype. A handful of patients with $\mathrm{HEV}$-associated neuralgic amyotrophy have received ribavirin and intravenous immunoglobulin with a variable outcome. Because of the variable natural history of neuralgic amyotrophy and the small number of cases involved, the efficacy of antiviral therapy remains to be established.

\section{Meningoencephalomyelitis}

There have only been 12 cases of HEV-associated cases reported, usually an encephalitis, often in solid organ transplant recipients, where there was a prominent ataxic syndrome. An associated meningitis or myelitis has also been reported. A peripheral component is common, including an AIDP-type syndrome, demyelinating neuropathy and a painful neuropathy. Viral RNA was recovered from cerebrospinal fluid (CSF) in many, suggesting direct invasion as a cause of the central nervous system illness, so it is possible that the peripheral nerve features are also direct effects and support this aetiology in the other peripheral nerve disorders. In immunocompromised patients, outcomes were poor, but recovery was usual in the others. Liver function tests were only mildly elevated.

\section{Other neurological associations}

A mononeuritis multiplex is the next most frequently reported neurological condition and is usually painful, asymmetric and asynchronous. ${ }^{25}$ The pathology is unknown, as nerve biopsies have not been undertaken. Myositis is rarely reported, but one severe case responded to ribavirin.

\section{Chance association or causality?}

We are all well aware of the dictum 'association does not imply causation'. Does HEV have a causal role in the neurological syndromes described above or is it just a chance association? Causality is difficult to prove, but our view is that there is a causal relationship, 
Table 2 Symptoms of acute hepatitis E caused by hepatitis E virus genotype 3

\begin{tabular}{lc}
\hline Symptom & Frequency (\%) \\
\hline Jaundice & 58 \\
\hline Malaise & 34 \\
Vomiting & 29 \\
\hline Abdominal pain & 26 \\
Anorexia & 23 \\
Myalgia & 14 \\
Fever & 11 \\
\hline Weight loss & 10 \\
Neurological & 8 \\
\hline Arthralgia & 7 \\
Miscellaneous* & 5 \\
\hline
\end{tabular}

Data derived from a hospital-based series of 106 patients with locally acquired hepatitis E from Southwest England 13. Patients presenting with neurological illness were younger and had a milder hepatitis than those patients presenting without neurological symptoms.

*Miscellaneous: back pain, diarrhoea, rash, and muscle weakness.

particularly in GBS, neuralgic amyotrophy and meningoencephalomyelitis. ${ }^{24} \mathrm{HEV}$ has been temporally associated with all three of these neurological illnesses from differing geographical areas and with differing genotypes. In one well-documented case of HEV-associated peripheral neuropathy in a patient with chronic HEV infection, neurological symptoms resolved following viral clearance. ${ }^{26}$ Finally, in our clinical practice, a combination of bilateral shoulder pain, abnormal liver function tests in a man aged 35-60 years strongly predicts HEV infection.

We do not know the mechanisms whereby HEV causes neurological injury. It could be immune-mediated, or HEV might be directly neurotropic. Some evidence suggests that $\mathrm{HEV}$ is neurotropic, and in some cases HEV RNA has been recovered from the CSF. ${ }^{24} 26$ The HEV quasispecies in the CSF was different to that recovered from the serum in one chronically infected patient. ${ }^{27}$ Recent in vitro and in vivo evidence shows that HEV grows well on a range of neurological cell lines and can cross the blood-brain barrier in animals. ${ }^{28} 29$

\section{CONCLUSIONS}

As neurologists, we tend to overlook non-neurological possibilities in our differential diagnosis. How often have we dismissed mildly elevated liver function tests as being a non-specific response to inflammation? Even our general medical colleagues may show a similar single-mindedness. For example, a significant minority of 'drug-related liver dysfunction' are HEV infections. ${ }^{30} \mathrm{HEV}$ is now recognised as a cause of peripheral nerve inflammatory disorders, notably AIDP and

\section{Box 1 Extrahepatic manifestations of hepatitis $\mathrm{E}$}

\author{
Neurological \\ - Guillain-Barré syndrome \\ - Neuralgic amyotrophy (brachial neuritis) \\ - Meningoencephalitis \\ - Mononeuritis multiplex \\ - Bell's palsy \\ - Vestibular neuritis \\ - Peripheral neuropathy \\ - Myositis \\ Haematological \\ - Thrombocytopenia \\ - Monoclonal immunoglobulin \\ - Cryoglobulinaemia \\ Nephrological \\ - Glomerulonephritis

\section{Miscellaneous} \\ - Acute pancreatitis \\ - Arthritis \\ - Autoimmune thyroiditis \\ Myocarditis
}

neuralgic amyotrophy, as well as mononeuritis multiplex, with a pathophysiology of a variable blend of autoimmune phenomenon and direct infection. An association with central nervous system manifestations is likely, particularly in solid organ transplant recipients, and may represent a direct infection.

Despite the nomenclature, it is important to emphasise that patients with HEV-associated neurological injury do not usually present with jaundice. We would recommend testing for HEV in any patient with AIDP, neuralgic amyotrophy, meningoencephalomyelitis, any likely inflammatory peripheral nerve disorder where liver function tests are elevated and possibly in any neurological disorder with unexplained increases in liver function tests. The role of HEV in other neurological disorders remains to be established, but these are

\section{Key points}

- Patients with hepatitis E virus (HEV)-associated neurological disease nearly always do NOT present with jaundice.

- All acute inflammatory demyelinating polyradiculoneuropathy and neuralgic amyotrophy-test for HEV (irrespective of liver function tests results).

- Abnormal liver function tests in any neurological disordertest for HEV.

- Bilateral shoulder pain in a male aged 30-60 years with abnormal liver function tests is HEV until proven otherwise.

- Unexplained meningoencephalitis-think of HEV. 
exciting times, and the full spectrum of associations will eventually unfold. In the meantime, please barbeque your pork sausages well.

Contributors BNM wrote the first draft, HRD amended and provided the figures and tables and JG referenced and further amended the paper.

Competing interests HRD has received travel and accommodation costs and consultancy fees from GSK, Wantai and Roche; travel accommodation and lecture fees from Merck, Gilead, GFE Blut $\mathrm{BmBh}$; travel and accommodation costs from the Gates Foundation and Medicins Sans Frontieres. BNM has received honoraria, lecture fees and conference fees from Eisai, GSK, Sanofi, Novartis and Biogen. RG has no competing interests to declare.

Patient consent It is a review article and not relevant.

Provenance and peer review Commissioned; externally peer reviewed. This paper was reviewed by Nick Davies, London, UK.

Data sharing statement All data used has been referenced in this paper.

(C) Article author(s) (or their employer(s) unless otherwise stated in the text of the article) 2017. All rights reserved. No commercial use is permitted unless otherwise expressly granted.

\section{REFERENCES}

1 Kamar N, Dalton HR, Abravanel F, et al. Hepatitis E virus infection. Clin Microbiol Rev 2014;27:116-38.

2 Kamar N, Bendall R, Legrand-Abravanel F, et al. Hepatitis E. Lancet 2012;379:2477-88.

3 Browne LB, Menkir Z, Kahi V, et al. Notes from the field: hepatitis $E$ outbreak among refugees from South

Sudan -Gambella, Ethiopia, April 2014-January 2015. MMWR Morb Mortal Wkly Rep 2015;64:537.

4 Dalton HR, Bendall R, Ijaz S, et al. Hepatitis E: an emerging infection in developed countries. Lancet Infect Dis 2008;8:698-709.

5 Barnaud E, Rogée S, Garry P, et al. Thermal inactivation of infectious hepatitis $\mathrm{E}$ virus in experimentally contaminated food. Appl Environ Microbiol 2012;78:5153-9.

6 Feagins AR, Opriessnig T, Guenette DK, et al. Inactivation of infectious hepatitis $\mathrm{E}$ virus present in commercial pig livers sold in local grocery stores in the United States. Int J Food Microbiol 2008;123(1-2):32-7.

7 Kamar N, Selves J, Mansuy J-M, et al. Hepatitis E virus and chronic hepatitis in organ-transplant recipients. N Engl J Med Overseas Ed 2008;358:811-7.

8 Dalton HR, Bendall RP, Keane FE, et al. Persistent carriage of hepatitis E virus in patients with HIV infection. N Engl J Med 2009;361:1025-7.

9 Hewitt PE, Ijaz S, Brailsford SR, et al. Hepatitis E virus in blood components: a prevalence and transmission study in southeast England. Lancet 2014;384:1766-73.

10 Zaaijer HL. No artifact, hepatitis $\mathrm{E}$ is emerging. Hepatology 2015;62:654.

11 Cleland A, Smith L, Crossan C, et al. Hepatitis E virus in scottish blood donors. Vox Sang 2013;105:283-9.

12 Hewitt P. Hepatitis E and Blood transfusion: NHSBT implementation of the recommendation to provide HEV screened blood components for certain patient groups. Blood and Transplant Matters 2016;49:4-5.
13 Woolson KL, Forbes A, Vine L, et al. Extra-hepatic manifestations of autochthonous hepatitis $\mathrm{E}$ infection. Aliment Pharmacol Ther 2014;40:1282-91.

14 Blasco-Perrin H, Madden RG, Stanley A, et al. Hepatitis E virus in patients with decompensated chronic liver disease: a prospective UK/French study. Aliment Pharmacol Ther 2015;42:574-81.

15 Péron JM, Abravanel F, Guillaume M, et al. Treatment of autochthonous acute hepatitis $\mathrm{E}$ with short-term ribavirin: a multicenter retrospective study. Liver Int 2016;36:328-33.

16 Sood A, Midha V, Sood N. Guillain-Barré syndrome with acute hepatitis E. Am J Gastroenterol 2000;95:3667-8.

17 Kamar N, Bendall RP, Peron JM, et al. Hepatitis E virus and neurologic disorders. Emerg Infect Dis 2011; 17:173-9.

18 Oomes PG, van der Meché FG, Kleyweg RP. Liver function disturbances in Guillain-Barré syndrome: a prospective longitudinal study in 100 patients. Dutch Guillain-Barré Study Group. Neurology 1996;46:96-100.

19 van den Berg B, van der Eijk AA, Pas SD, et al. Guillain-Barré syndrome associated with preceding hepatitis $\mathrm{E}$ virus infection. Neurology 2014;82:491-7.

20 Geurtsvankessel CH, Islam Z, Mohammad QD, et al. Hepatitis $\mathrm{E}$ and Guillain-Barre syndrome. Clin Infect Dis 2013;57:1369-70.

21 Fukae J, Tsugawa J, Ouma S, et al. Guillain-Barré and Miller Fisher syndromes in patients with anti-hepatitis E virus antibody: a hospital-based survey in Japan. Neurol Sci 2016;37:1849-51.

22 Stevens O, Claeys KG, Poesen K, et al. Diagnostic challenges and clinical characteristics of Hepatitis E virusassociated Guillain-Barré syndrome. JAMA Neurol 2017;74:26.

23 van Eijk JJ, Madden RG, van der Eijk AA, et al. Neuralgic amyotrophy and hepatitis E virus infection. Neurology 2014;82:498-503.

24 Dalton HR, Kamar N, van Eijk JJ, et al. Hepatitis E virus and neurological injury. Nat Rev Neurol 2016;12:77-85.

25 Perrin HB, Cintas P, Abravanel F, et al. Neurologic disorders in immunocompetent patients with autochthonous acute hepatitis E. Emerg Infect Dis 2015;21:1928-34.

26 Dalton HR, Keane FE, Bendall R, et al. Treatment of chronic hepatitis $\mathrm{E}$ in a patient with HIV infection. Ann Intern Med 2011;155:479-80.

27 Kamar N, Izopet J, Cintas P, et al. Hepatitis E virus-induced neurological symptoms in a kidney-transplant patient with chronic hepatitis. Am J Transplant 2010;10:1321-4.

28 Shi R, Soomro MH, She R, et al. Evidence of hepatitis E virus breaking through the blood-brain barrier and replicating in the central nervous system. J Viral Hepat 2016;23:930-9.

29 Drave SA, Debing Y, Walter S, et al. Extra-hepatic replication and infection of hepatitis $\mathrm{E}$ virus in neuronal-derived cells. $J$ Viral Hepat 2016;23:512-21.

30 Dalton HR, Fellows HJ, Stableforth W, et al. The role of hepatitis E virus testing in drug-induced liver injury. Aliment Pharmacol Ther 2007;26:1429-35. 
31 Hogema BM, Molier M, Slot E, et al. Past and present of hepatitis E in the Netherlands. Transfusion 2014;54:3092-6.

32 Slot E, Hogema BM, Riezebos-Brilman A, et al. Silent hepatitis E virus infection in Dutch blood donors, 2011 to 2012. Euro Surveill 2013;18:20550. pii: 20550.

33 Vollmer T, Diekmann J, Johne R, et al. Novel approach for detection of hepatitis $\mathrm{E}$ virus infection in German blood donors. J Clin Microbiol 2012;50:2708-13.

34 Fukuda S, Sunaga J, Saito N, et al. Prevalence of antibodies to hepatitis $\mathrm{E}$ virus among Japanese blood donors: identification of three blood donors infected with a genotype 3 hepatitis $\mathrm{E}$ virus. J Med Virol 2004;73:554-61.

35 Gallian P, Lhomme S, Piquet Y, et al. Hepatitis E virus infections in blood donors, France. Emerg Infect Dis 2014;20:1914-7.
36 Baylis SA, Gärtner T, Nick S, et al. Occurrence of hepatitis E virus RNA in plasma donations from Sweden, Germany and the United States. Vox Sang 2012;103:89-90.

37 Fischer C, Hofmann M, Danzer M, et al. Seroprevalence and incidence of hepatitis $\mathrm{E}$ in blood donors in Upper Austria. PLoS One 2015;10:e0119576.

38 Stramer SL, Moritz ED, Foster GA, et al. Hepatitis E virus: seroprevalence and frequency of viral RNA detection among US blood donors. Transfusion 2016;56:481-8.

39 Adlhoch C, Avellon A, Baylis SA, et al. Hepatitis E virus: assessment of the epidemiological situation in humans in Europe, 2014/15. J Clin Virol 2016;82:9-16. 